\title{
Bacterial Community Analysis of Two Neighboring Freshwater Lakes Originating from One Lake
}

\author{
Dabin Guo ${ }^{1,2}$, Jiechao Liang1, Wei Chen ${ }^{1}$, Jian Wang", Bin Ji1*, Shiyi Luo \\ ${ }^{1}$ Department of Water and Wastewater Engineering, School of Urban Construction, \\ Wuhan University of Science and Technology, Wuhan 430065 \\ ${ }^{2}$ School of Environmental Science \& Engineering, Huazhong University of Science and Technology, \\ Wuhan 430074 , China \\ ${ }^{3}$ State Key Laboratory of Physical Chemistry of Solid Surfaces and College of Chemistry and Chemical Engineering, \\ Xiamen University, Xiamen 361005, China
}

Received: 20 January 2020

Accepted: 16 March 2020

\begin{abstract}
Bacterial community compositions of two neighboring freshwater lakes (i.e. Inner Sand Lake and Sand Lake in Wuhan, China) originating from one lake were studied by triplicate sampling based on Illumina Miseq sequencing. The pollutant concentrations in Sand Lake were twice as in Inner Sand Lake generally. Proteobacteria mainly containing Betaproteobacteria and Alphaproteobacteria were most abundant in the two lakes. The most dramatic differences at phylum level were that Inner Sand Lake had a higher proportion of Bacteroidetes while Sand Lake had a higher proportion of Cyanobacteria. The eutrophic Sand Lake had more taxa as for Alpinimonas, Flavobacterium, Lautropia, Pelomonas, Pseudomonas, Sphingorhabdus, Candidatus Aquirestis and Vogesella. On the contrary, the oligotrophic Inner Sand Lake had more taxa as for Aeromonas, Bradyrhizobium, Fluviicola, Limnohabitans, Luteolibacter, Polynucleobacter, Pseudarcicella and Sediminibacterium. Correlation network analysis revealed that Pseudarcicella, Sediminibacterium, Luteolibacter, Aeromonas in fresh lakes were potential bacterial indicators of good-quality lakes. Conversely, Flavobacterium, Pseudomonas and Candidatus Aquirestis seemed to be bacterial indicators of bad-quality lakes. Results obtained from this study could gain more knowledge on freshwater lake ecosystems from the bacterial aspect.
\end{abstract}

Keywords: freshwater lakes, bacterial community, Pseudarcicella, eutrophication

\section{Introduction}

Water quality is crucial for freshwater lakes but urbanization usually has a negative impact on water quality [1]. The discharge of wastewater or treated

*e-mail: binji@wust.edu.cn wastewater can somehow change the lake ecosystem gradually by reducing water quality and the microbial abundance [2]. Currently, there have been more than two-thirds of urban lakes are suffering from different levels of pollution and eutrophication in Wuhan, China [3].

Research on the bacterial community compositions is beneficial for keeping good water quality as well as preventing algae blooming $[4,5]$ of the lakes. 
Bacteria contribute to the fundamental energy flow and biogeochemical cycling of lake ecosystems [6], which can be control agents against toxic cyanobacterial blooms [7] by interacting with specific phytoplankton [6]. Moreover, bacteria even have the capacity to move towards inorganic nutrients [8]. Thus, the strong adaptability and sensitive environmental perception allow the bacteria to play an indispensable role in lake ecosystems.

In this study, two neighboring freshwater lakes, namely Sand Lake and Inner Sand Lake, were studied in terms with the bacterial community and water quality. The two lakes were separated from one lake since the construction of Canton-Hankow Railway in 1907 of the Qing Dynasty in China. Currently, Sand Lake and Inner Sand Lake covers an area of 3.197 and 0.134 square kilometers, respectively, which were separated by Youyi Ave. The smaller Inner Sand Lake has
Table 1. Main chemical indexes of Inner Sand Lake (JD07) and Sand Lake (JD08).

\begin{tabular}{|c|c|c|}
\hline Sample ID & JD07 Mean/SD & JD08 Mean/SD \\
\hline $\mathrm{PH}$ & $6.95 / 0.02$ & $7.04 / 0.02$ \\
\hline $\mathrm{F}^{-}(\mathrm{mg} / \mathrm{L})$ & $0.022 / 0.03$ & $0.025 / 0.03$ \\
\hline $\mathrm{Cl}^{-}(\mathrm{mg} / \mathrm{L})$ & $0.725 / 0.18$ & $0.874 / 0.21$ \\
\hline $\mathrm{COD}(\mathrm{mg} / \mathrm{L})$ & $14.08 / 1.03$ & $28.34 / 3.06$ \\
\hline $\mathrm{NO}_{3}{ }^{-} \mathrm{N}(\mathrm{mg} / \mathrm{L})$ & $0.036 / 0.05$ & $0.059 / 0.08$ \\
\hline $\mathrm{NH}_{4}{ }^{+}-\mathrm{N}(\mathrm{mg} / \mathrm{L})$ & $0.422 / 0.10$ & $0.884 / 0.13$ \\
\hline $\mathrm{TN}^{(\mathrm{mg} / \mathrm{L})}$ & $0.616 / 0.14$ & $1.607 / 0.24$ \\
\hline $\mathrm{PO}_{4}{ }^{3-} \mathrm{P}(\mathrm{mg} / \mathrm{L})$ & $0.072 / 0.05$ & $0.101 / 0.04$ \\
\hline $\mathrm{TP}^{(\mathrm{mg} / \mathrm{L})}$ & $0.081 / 0.05$ & $0.141 / 0.07$ \\
\hline $\mathrm{SO}_{4}{ }^{2-}(\mathrm{mg} / \mathrm{L})$ & $1.255 / 0.20$ & $1.477 / 0.28$ \\
\hline
\end{tabular}

a)

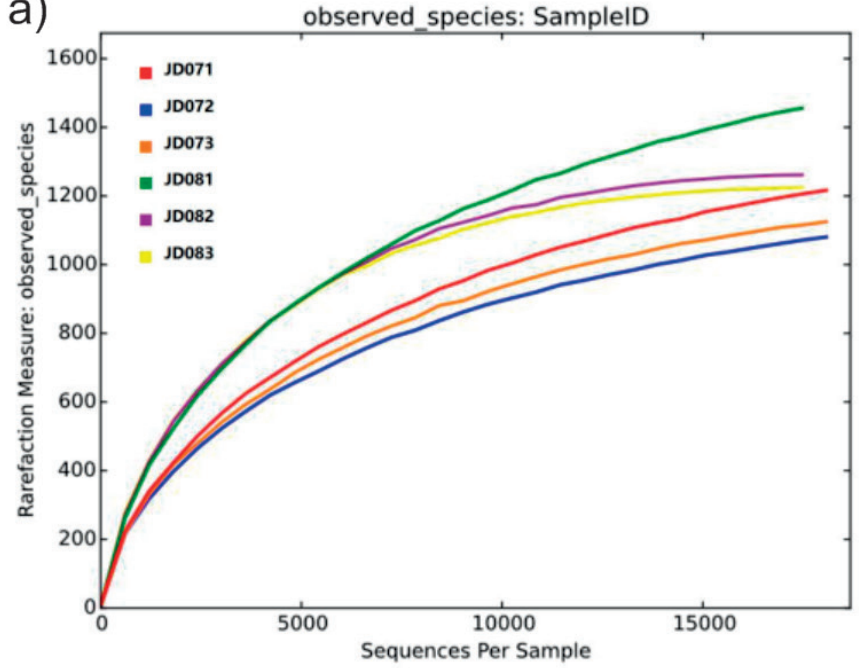

c)

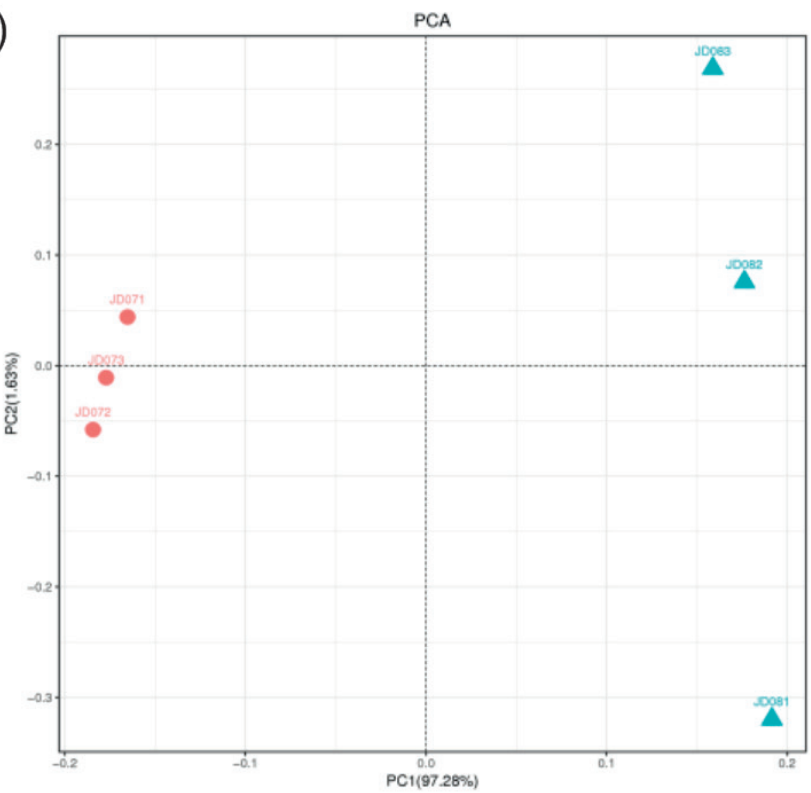

b)

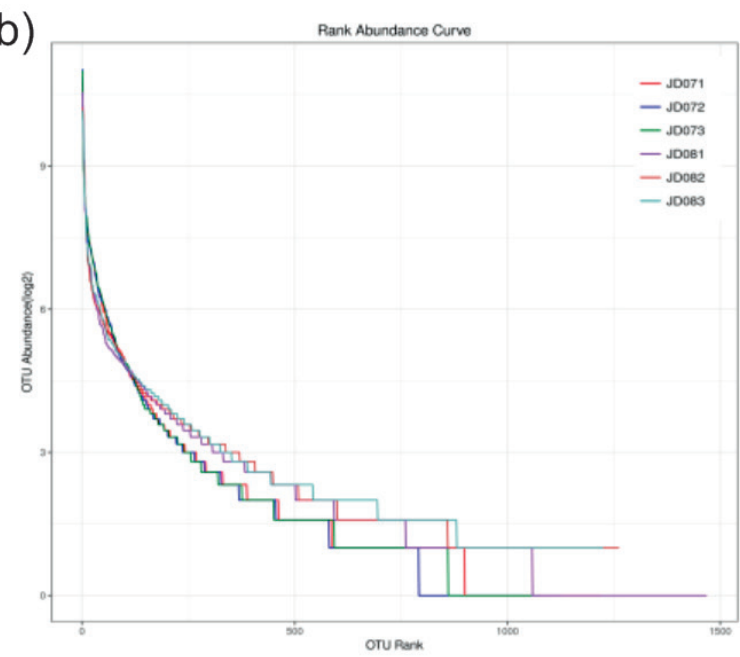

d)

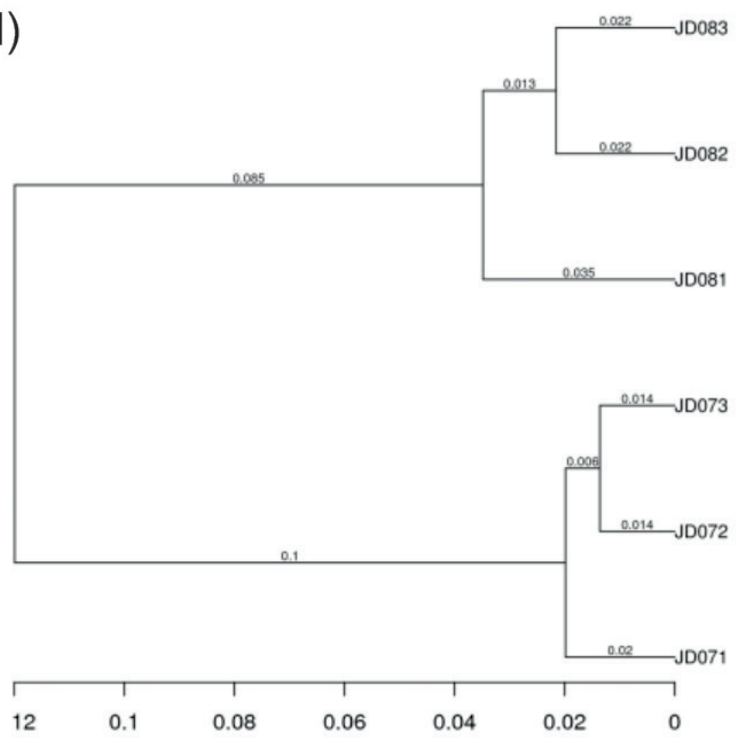

Fig. 1a) Rarefaction curves of operational taxonomic units; b) rank-abundance curves; c) Principal component analysis (PCA) showing the beta diversity among the samples; d) UPGMA clustering analysis graph based on weighted uniFrac distance matrix. 
Table 2 . The $\alpha$-diversity indices of the bacterial communities.

\begin{tabular}{|c|c|c|c|c|}
\hline & Chao1 & ACE & Simpson & Shannon \\
\hline JD071 & 1381.55 & 1488.09 & 0.9767 & 7.44 \\
\hline JD072 & 1281.03 & 1329.09 & 0.9742 & 7.28 \\
\hline JD073 & 1257.02 & 1328.49 & 0.9757 & 7.37 \\
\hline JD081 & 1748.42 & 1827.43 & 0.9788 & 7.83 \\
\hline JD082 & 1262.00 & 1262.00 & 0.9824 & 7.99 \\
\hline JD083 & 1225.00 & 1225.00 & 0.9845 & 8.09 \\
\hline
\end{tabular}

a better water quality due to the artificial remediation since 2013 by sewage interception, sediment clearing, hydrophyte, etc. The study aims to disclose the specific bacterial community compositions in the two lakes, to investigate the bacterial similarities and differences of the two lakes, and to associate the bacterial community with water quality of the two lakes. This study could gain more knowledge on freshwater lake ecosystems from the bacterial aspect.

\section{Experimental}

\section{Study Sites and Sampling}

The specific locations of the two sampling points were JD07 $\left(30^{\circ} 33^{\prime} 40.9^{\prime \prime} \mathrm{N}, 114^{\circ} 18^{\prime} 53.2^{\prime \prime} \mathrm{E}\right)$ and JD08 $\left(30^{\circ} 33^{\prime} 27.3^{\prime \prime} \mathrm{N}, 114^{\circ} 19^{\prime} 24.3^{\prime \prime} \mathrm{E}\right)$ for Inner Sand Lake and Sand Lake, respectively. Triplicated water samples $(500 \mathrm{~mL})$ were retrieved from each sampling site at the water depth of about $5 \mathrm{~cm}$ below the water surface. The samples were collected at 1-2 p.m. on December 22, 2017, the Winter Solstice Day. The average water temperatures of JD07 and JD08 were $14.5^{\circ} \mathrm{C}$ and $15.0^{\circ} \mathrm{C}$, respectively.

\section{Measurement of Water Biochemical Parameters}

The general biochemical parameters of collected water samples were analyzed and tested in $2 \mathrm{~h}$. About $100 \mathrm{~mL}$ raw water of each sample was filtered through a $25 \mathrm{~mm}$ diameter, $0.2 \mu \mathrm{m}$ filter membrane (Osmonics, Livermore, California, USA) and the filters were stored respectively at $-80^{\circ} \mathrm{C}$. The $\mathrm{pH}$ values were measured using a $\mathrm{pH}$ meter (OHAUS, ST3100). The Standard Methods [9] were used to determine ammonium nitrogen $\left(\mathrm{NH}_{4}^{+}-\mathrm{N}\right)$, total nitrogen $(\mathrm{TN})$, phosphate $\left(\mathrm{PO}_{4}^{3-}-\mathrm{P}\right)$, total phosphate (TP), nitrate nitrogen $\left(\mathrm{NO}_{3}^{-}-\mathrm{N}\right)$, and chemical oxygen demand (COD) of the water samples. Concentrations of $\mathrm{F}^{-}, \mathrm{Cl}^{-}$and $\mathrm{SO}_{4}^{2-}$ were tested by ion chromatograph (DIONEX-ICS-600, USA) [10]. The mean values of the biochemical parameters of JD07 and JD08 were determined based on JD071/JD072/JD073 and JD081/JD082/JD083, respectively.

\section{DNA Extraction, PCR Amplification and Miseq Sequencing}

The E.Z.N.A. soil DNA isolation kit (OMEGA Biotek Inc., Norcross, GA, USA) was applied to extract the total genome DNA [11], verified by $0.8 \%$ agarose gel electrophoresis. Fragment of the V4-V5 region of bacterial $16 \mathrm{~S}$ rRNA genes were amplified by using primers $515 \mathrm{~F}$ and $907 \mathrm{R}$. The procedures of PCR amplification and Miseq sequencing were conducted as described [2]. 16S rRNA gene sequences are available at NCBI Sequence Read Archive (accession numbers SRR8225311 for JD071, SRR8245887 for JD072, SRR8245884 for JD073, SRR8245885 for JD081, SRR8245886 for JD082, SRR8245975 for JD083).
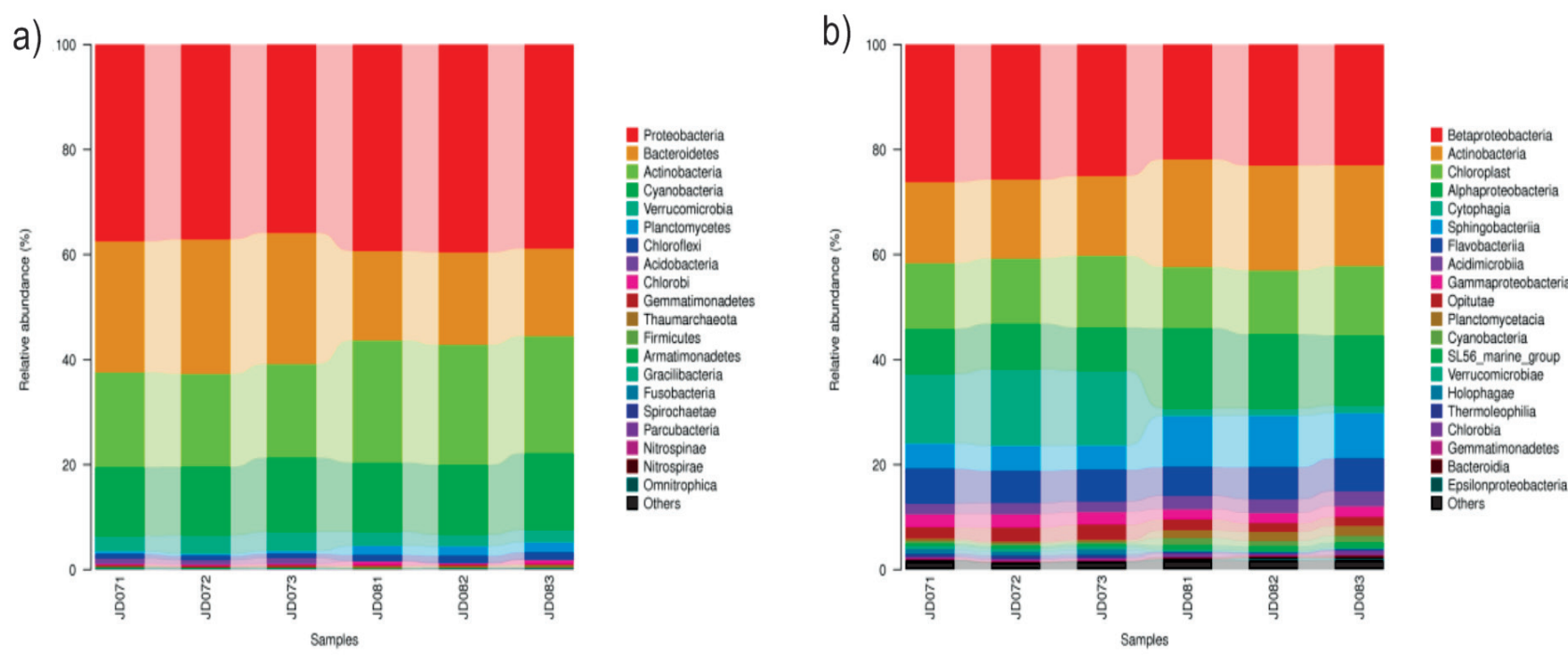

Fig. 2. Taxonomic classification of bacterial 16s rRNA gene reads at phylum level a) and class level b). 
a)
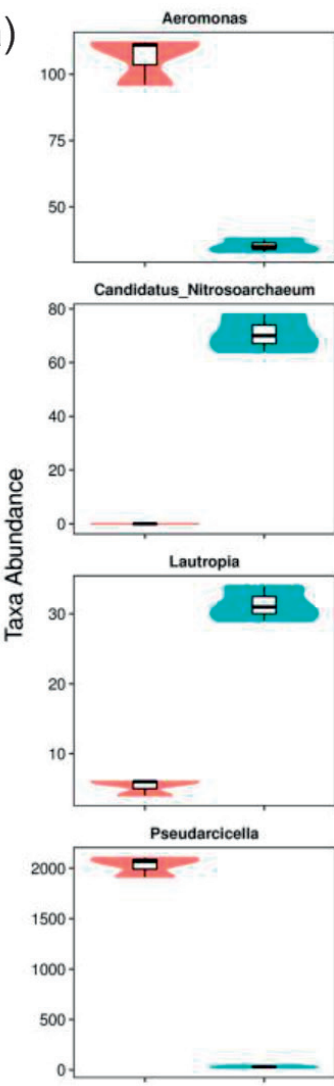

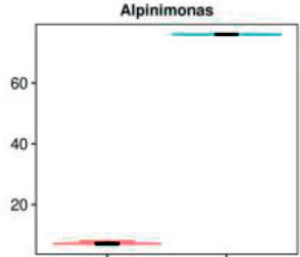

Candidatus_Rhodolune
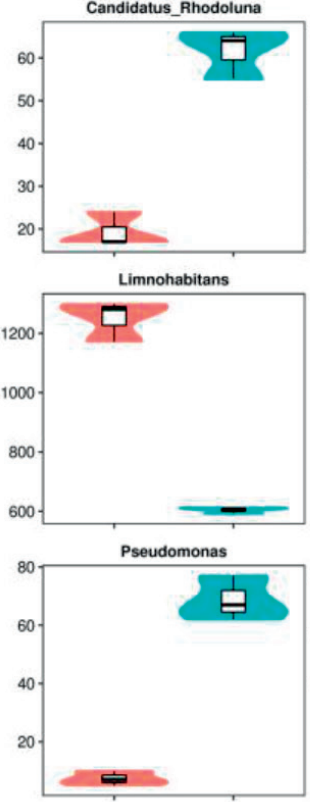

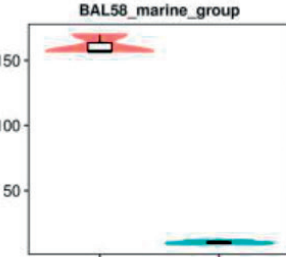

Flavobacterium

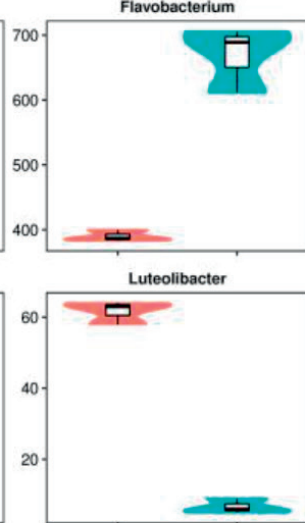

Sediminibacterium

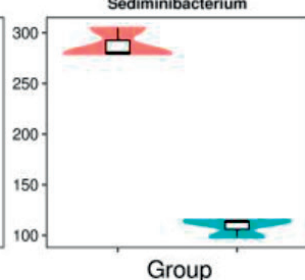

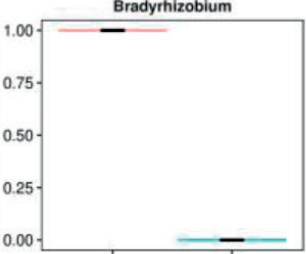

Fluviicola
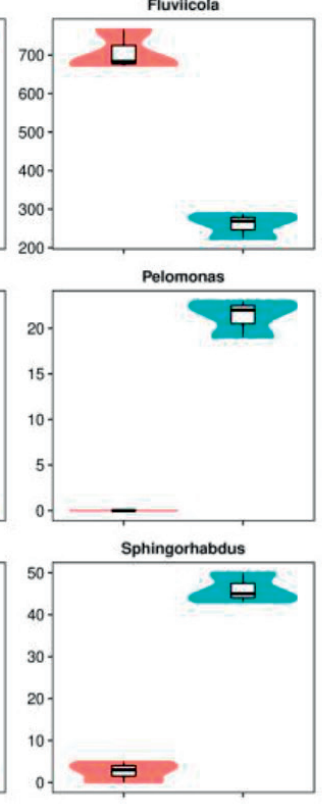

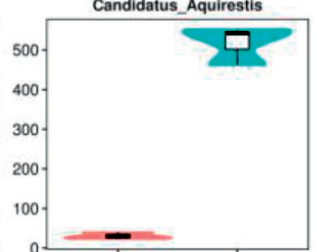

hgcl_clade
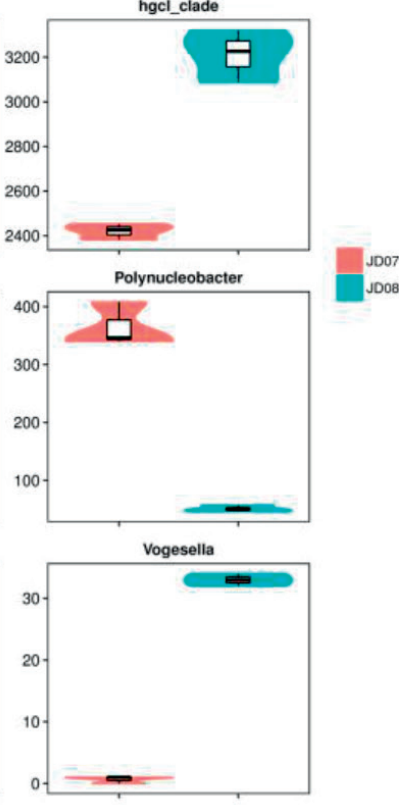

b)

Consensus Lineage

k_Bacteria;p_Proteobacteria;c_Betaproteobacteria;o_Burkholderiales;f_Comamonadaceae;g_uncultured;s_uncultured_bacterium k_Bacteria;p_Bacteroidetes;c_Cytophagia;o_Cytophagales;f_Cytophagaceae;g_Pseudarcicella;s_uncultured_bacterium

k_Bacteria;p_Cyanobacteria;c_Chloroplast;o_uncultured_bacterium;f_;__s__

k_Bacteria;P_Proteobacteria;c_Alphaproteobacteria;o_SAR11_clade;__Surface_1;g_uncultured_marine_bacterium;s_

$\mathrm{k}$ - Bacteria;p_Actinobacteria;c_Actinobacteria;o_Frankiales; $;$ _Sporichthyaceae;g_hgcl_clade;s_uncultured_bacterium

k_Bacteria;p_Bacteroidetes;c_Cytophagia;o_Cytophagales;__Cyclobacteriaceae;g_uncultured;s_uncultured_bacterium

k_Bacteria;P_Proteobacteria;c_Alphaproteobacteria;o_SAR11_clade;__LD12_freshwater_group;g_uncultured_bacterium;s_

k_Bacteria;P_Verrucomicrobia;c_Opitutae;o_Opitutae_vadinHA64;__unidentified;g_;s_

k_Bacteria;p_Bacteroidetes;c_Flavobacteriia;o_Flavobacteriales;f_Cryomorphaceae;g_Fluviicola;s_unidentified

k_Bacteria;p_Proteobacteria;c_Betaproteobacteria;o_Burkholderiales;f_Comamonadaceae;g_Limnohabitans;s_unidentified

k_Bacteria;p_Bacteroidetes;c_Sphingobacteriia;o_Sphingobacteriales;f_Saprospiraceae;g_Candidatus_Aquirestis;s_uncultured_bacterium

k_Bacteria;P_Actinobacteria;c_Actinobacteria;o_Frankiales;f_Sporichthyaceae;g_hgcl_clade;s_uncultured_bacterium

k_Bacteria;p_Proteobacteria;c_Betaproteobacteria;o_Burkholderiales;f_Burkholderiaceae;g_Polynucleobacter;s_uncultured_bacterium

k_Bacteria;p_Bacteroidetes;c_Sphingobacteriia;o_Sphingobacteriales;f_Chitinophagaceae;g_Filimonas;s_uncultured_bacterium

k_Bacteria;p_Bacteroidetes;c_Sphingobacteriia;o_Sphingobacteriales;f_Chitinophagaceae; __Sediminibacterium;s_uncultured bacterium

k-Bacteria;p_Proteobacteria;c Alphaproteobacteria;o Rhizobiales; $;$ MNG7;g uncultured bacterium;s

k_Bacteria;P_Proteobacteria;c_Alphaproteobacteria;o_Rhizobiales;__MNG7;g_ uncultured_bacterium;s_- _.

k_Bacteria;p__Actinobacteria;c_Actinobacteria;o_Frankiales;f_Sporichthyaceae;g_hgcl_clade;s_uncultured_bacterium

k_Bacteria;p_Proteobacteria;c_Alphaproteobacteria;o_Sphingomonadales;__unidentified;g_unidentified;s_unidentified

k_Bacteria;p_Bacteroidetes;c_Sphingobacteriia;o_Sphingobacteriales;f_Chitinophagaceae;g_Dinghuibacter;s_unidentified

k_Bacteria;p_Cyanobacteria;c_Chloroplast;o_unidentified;f_;_;s_

k_Bacteria;p_Actinobacteria;c_Actinobacteria;o_Frankiales;f_Sporichthyaceae;g_hgcl_clade;s_uncultured_bacterium

k_Bacteria;p_Planctomycetes;c_Planctomycetacia;o_Planctomycetales;f_Planctomycetaceae;g_uncultured;s_unidentified
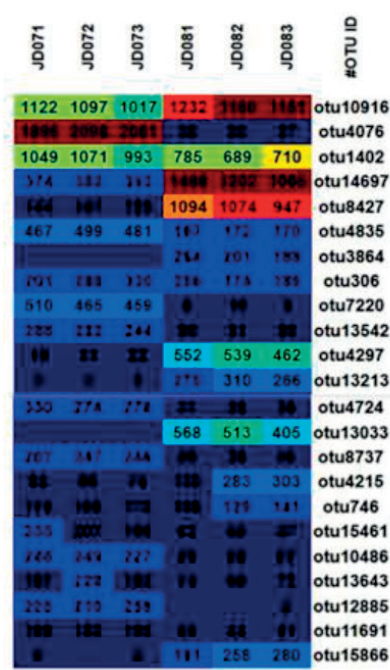

Fig. 3. a) Top 20 taxa with the most significant difference between Inner Sand Lake and Sand Lake by Metastats. b) Network inference based on the interrelationship among bacterial community.

\section{Data Analysis}

The QIIME (v1.8.0) pipeline and R software were used to analyze the sequencing data. UPGMA clustering analysis of weighed UniFrac distance matrix was carried out. Taxa abundances at the genus level were compared among samples by Metastats and visualized as violin plots. The Spearman's rank correlation coefficients were calculated and the network inference was constructed $(\rho>0.6, P<0.01)$ [10]. Samples were compared at genus level by Mothur based
Metastats (http://metastats.cbcb.umd.edu/) $\quad(p<0.05)$ [12]. The OTU hot map was constructed by using QIIME [13].

\section{Results and Discussion}

\section{Water Properties}

As shown in Table 1, Inner Sand Lake had a much better water quality than Sand Lake as indicated by 


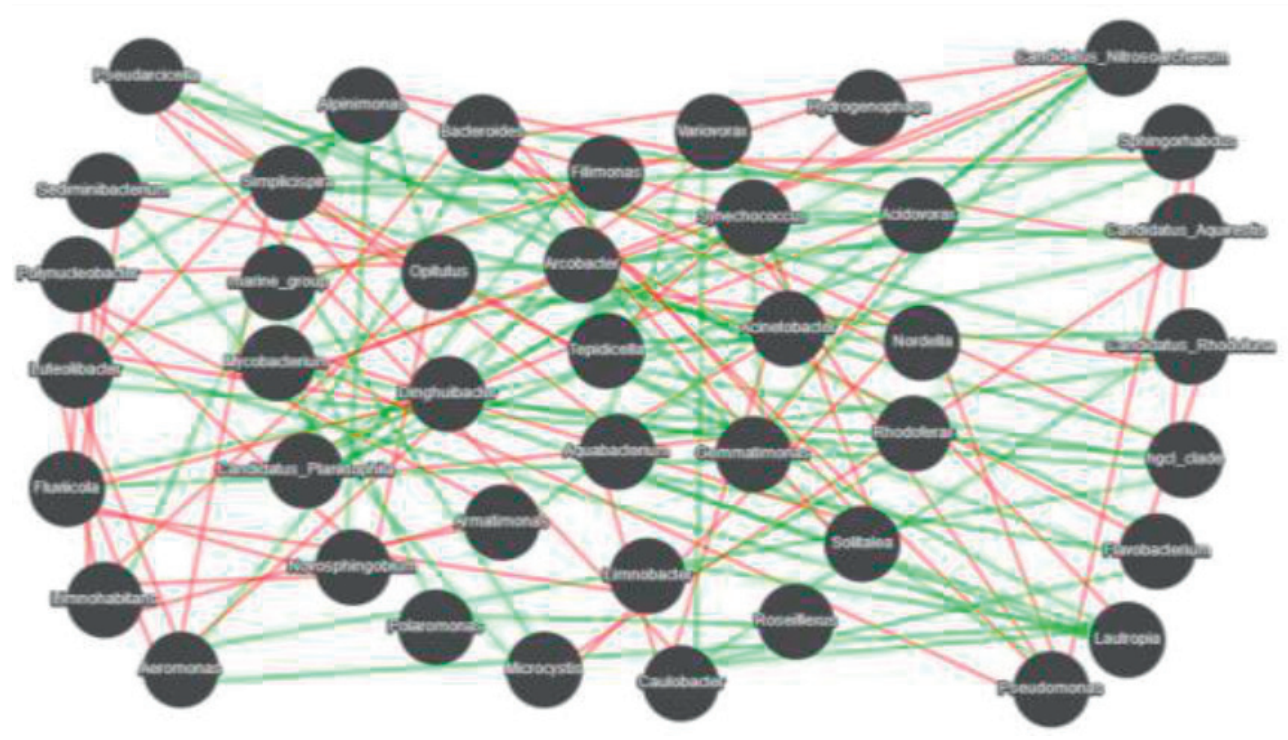

Fig. 4. Network inference based on the interrelationship among top bacterial species.

the biochemical parameters. In general, COD, nitrogen and phosphorus in Inner Sand Lake were half the values of those in Sand Lake. TN/TP ratios of Inner Sand Lake and Sand Lake were 7.6 and 11.4, respectively. Excessive nitrogen and phosphorus could cause nuisance growth of algae and other aquatic plants [14, 15], while both the dissolved carbon and nutrition were determining factors for the lake ecosystem [16, 17]. Among the factor,s phosphorus was believed to be the key element for eutrophication [18]. The nitrogen in Inner Sand Lake was deficient according to N-deficient growth of TN: TP $<9$ as reported [19]. Contrarily, the TN/TP ratio of 11.4 was favorable for phytoplankton growth [20] in Sand Lake. Moreover, Inner Sand Lake had lower concentrations of typical anions $\left(\mathrm{F}^{-}, \mathrm{Cl}^{-}\right.$and $\left.\mathrm{SO}_{4}^{2-}\right)$ than Sand Lake $(\mathrm{p}<0.05)$, suggesting that Inner Sand Lake had a smaller salinity.

\section{Abundance and Diversity of Bacterial Communities}

A total of 307,755 high-quality $16 \mathrm{~S}$ rRNA sequence reads were yielded for the six samples. Rarefaction analysis showed that the diversity of bacterial community was well captured [2] at the depth of sequencing used in this study (Fig. 1a). The length of the curve revealed that the sequencing depth of JD08 was slightly deeper than JD07. The evenness of microbial communities of JD08 was slightly higher than JD07 (Fig. 1b).

It could be inferred that the richness (Chao 1 and ACE) and biodiversity (Simpson and Shannon) showed no obvious differences of the two lakes as shown in Table 2. Fig. 1c) indicated that the distance of JD07 between the three repeating samples was closer than that of JD08, indicating that the similarity of microbial community structure between the three replicates in
Inner sand Lake (JD07) was higher than Sand Lake (JD08). The Weighted UniFrac analysis (Fig. 1d) indicated that samples of JD072 and JD073 were the most similar as the shortest branching length between the two samples [21].

\section{Bacterial Community Structure}

The Miseq sequencing results revealed that the dominating phyla were highly similar in the duplications of JD07 and JD08 (Fig. 2a). Similar to plateau freshwater lakes [22], the highest abundant phylum was found to be Proteobacteria in Inner Sand Lake (36.8\%) and Sand Lake (39.2\%). The most dramatic differences were that Inner Sand Lake had a higher proportion of Bacteroidetes while Sand Lake had a higher proportion of Cyanobacteria. Cyanobacteria blooming were always related to eutrophication of lakes [23]. The results also suggested that Cyanobacteria might inhibit the growth of Bacteroidetes [2].

At the class level, it could be found that the phylum Proteobacteria mainly consisted of Betaproteobacteria (24.1\%) and Alphaproteobacteria (11.3\%), followed by Gammaproteobacteria (2.2\%) (Fig. 2b), which was different from those of plateau freshwater lakes [22]. A higher proportion of Alphaproteobacteria (14.2\%) of Sand Lake could be found, which was reported to be dominant in eutrophic lake [24]. The phylum Bacteroidetes contains four classes of Bacteroidia, Flavobacteriia, Sphingobacteriia and Cytophagia. The taxa of Cytophagia in Inner Sand Lake were abundant $(14.0 \%)$, which was accorded with oligotrophic lake [25]. Oppositely, the taxa of Sphingobacteriia in Sand Lake were dominant $(9.4 \%)$, whose growth was related to the freshly leached dissolved organic carbon [26]. Hence, it could be speculated that the Cytophagia was favorable for lakes with good water quality and that 
the Sphingobacteriia was associated with eutrophication of fresh lakes.

\section{Significant Differences of Bacterial Communities of the Two Lakes}

Significant differences of bacterial communities of the two lakes were further studied. The top 20 taxa with the most significant difference between Inner Sand Lake and Sand Lake were listed in Fig. 3a), which showed that the Sand Lake had more taxa as for Alpinimonas, Flavobacterium, Lautropia, Pelomonas, Pseudomonas, Sphingorhabdus, Candidatus Aquirestis and vogesella. For example, a diverse freshwater Flavobacteria community was reported in eutrophic lakes [27]. On the contrary, Inner Sand Lake had more taxa as for Aeromonas, Bradyrhizobium, Fluviicola, Limnohabitans, Luteolibacter, Polynuccleobacter, Pseudarcicella and Sediminibacterium. Furthermore, the taxa over 600 OUTs presented in Fig. 3b) indicated the main taxa with significant abundant differences of the two lakes. It could be concluded that Pseudarcicella was the most significant indicator of a lake with good quality water. Indeed, Pseudarcicella was the representative genus of Lake Garda [28] and Three Gorges Reservoir [29] with good quality water.

\section{Network Inference Based on the Interrelationship Among Bacterial Community}

Correlation network analysis at genus level could reveal the interaction patterns of co-occurrence or co-exclusion among community members (Fig. 4). It indicated that Sediminibacterium favored the growth of Fluviicola and inhibited the growth of the potential eutrophic indicator of Alpinimonas and Candidatus Aquirestis. Moreover, Sediminibacterium could inhibit the growth of Microcystis. Luteolibacter had a possible collaboration with Fluviicola and Aeromonas. Combined Fig. 3 and Fig. 4, we could speculate that Pseudarcicella, Sediminibacterium, Luteolibacter, Aeromonas in fresh lakes might contribute to a goodquality lake. Conversely, Flavobacterium, Pseudomonas and Candidatus Aquirestis might contribute to the lake eutrophication.

\section{Conclusions}

This study reported the bacterial community compositions of two neighboring freshwater lakes at different trophic status originating from one lake in winter by triplicate sampling of surface water at two sampling sites. The similarities, differences and interrelationship of bacterial communities were characterized. It was found that the dominant aqueous Pseudarcicella was a potential indicator for lakes with good-quality water.

\section{Acknowledgements}

This research was financially supported by Open fund of Changjiang Academy of Sciences (CKWV2018490/KY), the Project of Key Laboratory of Healthy and Freshwater Aquaculture, Ministry of Agriculture (ZJK201810), the Science and Technology Research Project of Hubei Provincial Department of Education (Q20171107) and the Headmaster Funds of Xiamen University (20720170102).

\section{Conflict of Interest}

The authors declare no conflict of interest.

\section{References}

1. CHEN S., HE H., ZONG R., LIU K., YAN M., XU L., MIAO Y. Geographical patterns of algal communities associated with different urban lakes in China. International Journal of Environmental Research and Public Health, 17, 3, 2020.

2. JI B., HUI Q., GUO S., WEI C., ZHANG X., LIANG J. Bacterial communities of four adjacent fresh lakes at different trophic status. Ecotoxicology \& Environmental Safety, 157, 2018.

3. ZHANG Y., SONG C., JI L., LIU Y., XIAO J., CAO X., ZHOU Y. Cause and effect of N/P ratio decline with eutrophication aggravation in shallow lakes. Science of the Total Environment, 627, 2018.

4. TANG X., CHAO J., GONG Y., WANG Y., WILHELM S., GAO G. Spatiotemporal dynamics of bacterial community composition in large shallow eutrophic Lake Taihu: High overlap between free-living and particle-attached assemblages: Overlap between FL and PA bacterial communities 2017.

5. PARULEKAR N.N., KOLEKAR P., JENKINS A., KLEIVEN S., UTKILEN H., JOHANSEN A., SAWANT S., KULKARNI-KALE U., KALE M., SÆBØ M. Characterization of bacterial community associated with phytoplankton bloom in a eutrophic lake in South Norway using 16S rRNA gene amplicon sequence analysis. Plos One, 12, 3, 2017.

6. PAVER S.F., HAYEK K.R., GANO K.A., FAGEN J.R., BROWN C.T., DAVIS-RICHARDSON A.G., CRABB D.B., RICHARD R.P., ADRIANA G., TRIPLETT E.W. Interactions between specific phytoplankton and bacteria affect lake bacterial community succession. Environmental Microbiology, 15, 9, 2013.

7. MIYASHITA Y., HAGIWARA T., IMAI I. The existence of cyanobactericidal bacteria and growth-inhibiting bacteria on water plants in Lake Ohnuma, Japan. Limnology, 2018.

8. DENNIS P.G., SEYMOUR J., KUMBUN K., TYSON G.W. Diverse populations of lake water bacteria exhibit chemotaxis towards inorganic nutrients. ISME Journal, 7, 8, 2013.

9. LENORE S., CLESCERI A., GREENBERG A., ANDREW E., RAND M. Standard Methods for Examinations of Water and Wastewater, $21^{\text {st }}$ ed. American Public Health Association, Washington, DC., 2005. 
10. YAN M., CHEN S., HUANG T., LI B., LI N., LIU K., ZONG R., MIAO Y., HUANG X. Community Compositions of Phytoplankton and Eukaryotes during the Mixing Periods of a Drinking Water Reservoir: Dynamics and Interactions. International Journal of Environmental Research and Public Health, 17, 4, 2020.

11. SU X., XUE B., WANG Y., HASHMI M.Z., LIN H., CHEN J., MEI R., WANG Z., SUN F. Bacterial community shifts evaluation in the sediments of Puyang River and its nitrogen removal capabilities exploration by resuscitation promoting factor. Ecotoxicology and Environmental Safety, 179, 2019.

12. WHITE J.R., NAGARAJAN N., POP M. Statistical Methods for Detecting Differentially Abundant Features in Clinical Metagenomic Samples. Plos Computational Biology, 5, 4, 2009.

13. ZHANG H., FENG J., CHEN S., ZHAO Z., LI B., WANG Y., JIA J., LI S., WANG Y., YAN M. Geographical patterns of nirS gene abundance and nirS-type denitrifying bacterial community associated with activated sludge from different wastewater treatment plants. Microbial Ecology, 77, 2, 2019.

14. LEWIS W.M., WURTSBAUGH W.A., PAERL H.W. Rationale for Control of Anthropogenic Nitrogen and Phosphorus to Reduce Eutrophication of Inland Waters. Environmental Science \& Technology, 45, 24, 2011.

15. TEUFEL A.G., LI W., KISS A.J., MORGAN-KISS R.M. Impact of nitrogen and phosphorus on phytoplankton production and bacterial community structure in two stratified Antarctic lakes: a bioassay approach. Polar Biology, 40, 5, 2017.

16. KELLERMAN A.M., KOTHAWALA D.N., DITTMAR T., TRANVIK L.J. Persistence of dissolved organic matter in lakes related to its molecular characteristics. Nature Geoscience, 8, 2015.

17. CORMAN J.R., BERTOLET B.L., CASSON N.J., SEBESTYEN S.D., KOLKA R.K., STANLEY E.H. Nitrogen and Phosphorus Loads to Temperate Seepage Lakes Associated With Allochthonous Dissolved Organic Carbon Loads. Geophysical Research Letters, 45, 11, 2018.

18. SCHINDLER D.W., CARPENTER S.R., CHAPRA S.C., HECKY R.E., ORIHEL D.M. Reducing Phosphorus to Curb Lake Eutrophication is a Success. ENVIRONMENTAL SCIENCE \& TECHNOLOGY, 50, 17, 2016.

19. GUILDFORD S.J., HECKY R.E. Total Nitrogen, Total Phosphorus, and Nutrient Limitation in Lakes and
Oceans: Is There a Common Relationship? Limnology \& Oceanography, 45, 6, 2000.

20. SØNDERGAARD M., LAURIDSEN T.L., JOHANSSON L.S., JEPPESEN E. Nitrogen or phosphorus limitation in lakes and its impact on phytoplankton biomass and submerged macrophyte cover. Hydrobiologia, 795, 1, 2017.

21. SVENSSON K., PARUCH L., GABY J.C., LINJORDET R. Feeding frequency influences process performance and microbial community composition in anaerobic digesters treating steam exploded food waste. Bioresource Technology, 269, 2018.

22. ZHANG J., YANG Y., ZHAO L., LI Y., XIE S., LIU Y. Distribution of sediment bacterial and archaeal communities in plateau freshwater lakes. Applied Microbiology and Biotechnology, 99, 7, 2015.

23. PAERL H.W., PAUL V.J. Climate change: Links to global expansion of harmful cyanobacteria. Water Research, 46, $5,2012$.

24. CAI H., JIANG H., KRUMHOLZ L.R., YANG Z. Bacterial Community Composition of Size-Fractioned Aggregates within the Phycosphere of Cyanobacterial Blooms in a Eutrophic Freshwater Lake. PloS One, 9, 8, 2014.

25. SUN Y., WANG S., NIU J. Microbial community evolution of black and stinking rivers during in situ remediation through micro-nano bubble and submerged resin floating bed technology. Bioresource Technology, 258, 2018.

26. ATTERMEYER K., TITTEL J., ALLGAIER M., FRINDTE K., WURZBACHER C., HILT S., KAMJUNKE N., GROSSART H. Effects of Light and Autochthonous Carbon Additions on Microbial Turnover of Allochthonous Organic Carbon and Community Composition. Microbial Ecology, 69, 2, 2015.

27. ALEXANDER E., STEFAN B. Flavobacteria blooms in four eutrophic lakes: linking population dynamics of freshwater bacterioplankton to resource availability. Applied \& Environmental Microbiology, 73, 11, 2007.

28. SALMASO N., ALBANESE D., CAPELLI C., BOSCAINI A., PINDO M., DONATI C. Diversity and Cyclical Seasonal Transitions in the Bacterial Community in a Large and Deep Perialpine Lake. Microbial Ecology, 76, $1,2018$.

29. LI Z., LU L., GUO J., YANG J., ZHANG J., HE B., $\mathrm{XU}$ L. Responses of spatial-temporal dynamics of bacterioplankton community to large-scale reservoir operation: a case study in the Three Gorges Reservoir, China. Scientific Reports, 7, 2017. 